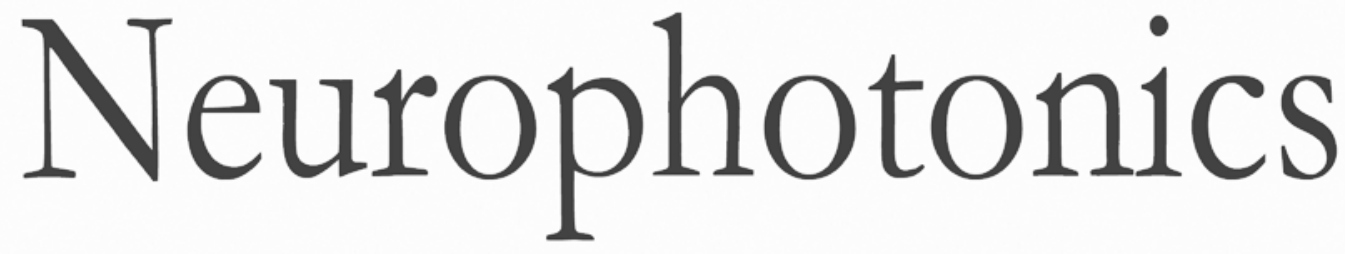

\title{
Errata: Hemodynamic response to burst-suppressed and discontinuous electroencephalography activity in infants with hypoxic ischemic encephalopathy
}

Maria Chalia

Chuen Wai Lee

Laura A. Dempsey

Andrea D. Edwards

Harsimrat Singh

Andrew W. Michell

Nicholas L. Everdell

Reuben W. Hill

Jeremy C. Hebden

Topun Austin

Robert J. Cooper 


\title{
Errata: Hemodynamic response to burst-suppressed and discontinuous electroencephalography activity in infants with hypoxic ischemic encephalopathy
}

\author{
Maria Chalia, ${ }^{a, b}$ Chuen Wai Lee, ${ }^{a, b}$ Laura A. Dempsey, ${ }^{a, c}$ Andrea D. Edwards, ${ }^{a, b}$ Harsimrat Singh, ${ }^{a, c}$ \\ Andrew W. Michell, ${ }^{d}$ Nicholas L. Everdell, ${ }^{a, c}$ Reuben W. Hill,c Jeremy C. Hebden, ${ }^{a, c}$ Topun Austin, ${ }^{a, b}$ and \\ Robert J. Cooper ${ }^{a, c}$ \\ ${ }^{a}$ Cambridge University Hospitals NHS Foundation Trust, The Rosie Hospital, The Evelyn Perinatal Imaging Centre, neoLAB, Cambridge \\ Biomedical Campus, Hills Road, Cambridge CB2 OQQ, United Kingdom \\ ${ }^{\mathrm{b} C}$ Cambridge University Hospitals NHS Foundation Trust, The Rosie Hospital, Department of Neonatology, Cambridge Biomedical Campus, \\ Hills Road, Cambridge CB2 OQQ, United Kingdom \\ 'University College London, Department of Medical Physics and Biomedical Engineering, Malet Place Engineering Building, Gower Street, \\ London WC1E 6BT, United Kingdom \\ ${ }^{d}$ Cambridge University Hospitals NHS Foundation Trust, Department of Clinical Neurophysiology, Cambridge Biomedical Campus, \\ Hills Road, Cambridge CB2 OQQ, United Kingdom
}

[DOI: 10.1117/1.NPh.3.3.039802]

This paper [Neurophoton 3(3), 031408 (2016)] was originally published with redundant video still images in Figs. 10 and 11. Those videos have been incorporated into the previous Figs. 6 and 8, and Figs. 10 and 11 have been deleted.

The article was corrected online on 4 May 2016. It appears correctly in print. 